DOI https://doi.org/10.30525/978-9934-26-113-8-4

\title{
СОСТОЯНИЕ ПРОБЛЕМЫ ДИАГНОСТИКИ И КОМПЛЕКСНОГО ЛЕЧЕНИЯ БОЛЬНЫХ \\ С ТУННЕЛЬНЫМ СИНДРОМОМ КАРПАЛЬНОГО КАНАЛА НА СОВРЕМЕННОМ ЭТАПЕ
}

\author{
Военный И. В. \\ аспирант \\ Национальный медицинский университет имени А. А. Богомольиа \\ Рушай А. К. \\ доктор медиџинских наук, профессор \\ Национальный медицинский университет имени А. А. Богомольия \\ Лисайчук Ю. С. \\ доктор медицинских наук, профессор \\ Национальный медицинский университет имени А. А. Богомольияа
}

Ковальчук В. С.

кандидат медицинских наук, доцент

Национальный медицинский университет имени А. А. Богомольйа

г. Киев, Украина

Введение. Синдром сдавления срединного нерва (карпальный туннельный синдром КТС) занимает лидирующие положение среди компрессионных невропатий и в структуре туннельных синдромов верхней конечности занимает до $80-80,3 \%[1,2,3]$. Причиной поздних обращений является недостаточная осведомленность врачей о клинике туннельных невропатий и способах их диагностики на начальных стадиях заболевания, длительное необоснованное консервативное лечение. Проблема далека от окончательного решения.

Цель обзора. Систематизировать современные представления о факторах риска развития КТС, меры профилактики, лечебные мероприятия и наметить наиболее перспективные направления решения проблемы лечения данной патологии.

Состояние вопроса по данным литературы. Основополагающим моментом в патогенезе развития невропатии лежит увеличение внутритканального давления, диагностика на ранней стадии развития заболевания представляет определенные трудности. В дальнейшем 
клиническая картина становится более выраженной, однако и на этой стадии диагноз требует уточнения.

Клинические проявления обусловлены нарушением функции срединного неи уточнить рва. Типичным является болевой синдром и нарушение чувствительности зоны иннервации срединного нерва. Предложенные общепринятые клинико-диагностические тесты достаточно информативны. Инструментальные методы диагностики, по мнению большинство авторов, позволяют объективизировать и уточнить полученные данные. Так, электромионейрография ЭНМГ достаточно информативна в $49-84 \%$ случаев $[4,5,6]$.

В инструментальной диагностике туннельных синдромов ведущее место занимает ультрасонография, с помощью которой можно оценить морфологию как туннеля, так и пораженного срединного нерва $[7,8,9]$.

Золотым стандартом инструментального подтверждения диагноза «КТС» является электронейромиография (ЭНМГ). Разработаны нейрофизиологические критерии тяжести КТС, позволяющие не только подтвердить диагноз, но и определить степень выраженности локального нарушения проведения возбуждения по нерву в месте компрессии. Ультразвуковое исследование срединного нерва позволяет визуализировать срединный нерв на уровне лучезапястного сустава, дополнительно подтвердить его компрессию в канале, но главное, исключить иные причины повреждения срединного нерва на этом уровне, в том числе объемные образования [10]. Высокую достоверность и воспроизводимость продемонстрировали 2 ультразвуковых показателя: увеличение площади поперечного сечения срединного нерва на уровне гороховидной кости (дистальная складка запястья) >9,8 мм2 [11] и усиление васкуляризации нерва в месте компрессии $[12,13]$.

Наиболее часто используется клинико-гистопатологическая классификация туннельных синдромов, предложенная Mackinnon S., Dellon A.L. в 1993 году, которые выделяли 3 стадии компрессии нерва.

1 стадия - характеризуется интраневральным отеком в ответ на увеличение давления в туннеле. Клинически выявляются преходящие боли мышц. Симптомы возникают только при провокационных тестах, во время сна, после работы.

2 стадия - появляется утолщение соединительно-тканных оболочек нерва (фиброз) и более выраженное сдавление миелинизированных волокон с демиелинизацией. Повышен порог вибрационной чувствительности, отчетлива слабость мышц, но симптомы преходящие, нет постоянных парестезии, 2-х точечный тест дискриминационной чувствительности не изменен, атрофии мышц отсутствуют.

3 стадия - валлеровская дегенерация миелинизированных волокон, аксонопатия. Присоединяются постоянные парестезии, снижается 20 
плотность кожной иннервации, (повышены результаты 2-х точечного теста вплоть до анестезии кожи), появляются мышечные атрофии.

При изучении клинической картины, туннельных невропатий дифференцировать 1 и 2 стадии заболевания практически не представлялось возможным, даже при использовании современных клинических тестов.

Выделяют следующие виды туннельных невропатий.

Острые (компрессионные, токсические, аутоиммунные):

- развитие симптомов происходит в течение нескольких дней до 4 недель;

- чаще являются результатом травмы (вследствие непосредственного действия травмирующего агента, быстро нарастающей гематомы или отека, за счет сдавления обломками костей или в результате вывихов);

- могут быть ятрогенными (как следствие сдавления жгутом или гипсовой повязкой, результат неправильных укладок на операционном столе, сдавления фиксирующими пластинами и др.);

- результат неправильного положения конечностей (сдавление конечности во время сна и т.п.);

- вследствие резкого перенапряжения мышц.

Подострые (в течение нескольких недель - токсические, вследствие системных заболеваний);

Хронические, в т.ч. и рецидивирующие (метаболические) развиваются в течение нескольких месяцев или лет.

В настоящее время выделяют три варианта декомпрессии срединного нерва в карпальном канале: открытая, из мини-доступа и эндоскопическая, а также их модификации. Открытая декомпрессия является наиболее распространенным оперативным вмешательством. Исследования, в которых выполнялось сравнение эффективности различных оперативных методик, противоречивы в своих заключениях. Так, М.В. Larsen и соавт. (2013) при сравнении декомпрессии открытым методом, из мини-доступа и эндоскопическим отмечают одинаковые результаты через 4 мес после операции [14]. В мета-анализе, проведенном D. Zuo (2015), указывается, что открытая и эндоскопическая операции имеют сравнительно одинаковые положительные результаты и уровень послеоперационных осложнений. Н.J. Kang (2013) отметил, что 34 (65\%) больных из 52, которым была проведена билатеральная декомпрессия (с одной стороны из мини-доступа, с другой - эндоскопическая), предпочли бы эндоскопическую операцию [15]. Также многие авторы описывают низкий процент рецидивов и более быстрое восстановление трудоспособности после выполнения эндоскопической декомпрессии срединного нерва [16,17]. В мета-анализе, проведенном Е.T. Sayegh и R.J. Strauch в 2015 г., описывается одинаковый эффект при сравнении 
результатов открытой и эндоскопической декомпрессии в отдаленном периоде, однако эндоскопическая технология позволяет пациентам раньше возвращаться к труду. Кроме того, авторы описывают низкие риски формирования болезненного послеоперационного рубца и высокий риск повреждения срединного нерва при проведении эндоскопической операции [19].

\section{Заключение. Выводы.}

Критически оценивая данные обзора научной литературы, мы пришли к следующим выводам. Отсутствует объективный и легко воспроизводимый на практике алгоритм диагностической тактики ведения больных с туннельным карпальным синдромом и выбора метода их лечения.

Основными направлениями улучшения результатов лечения туннельного карпального синдрома является прогнозирование и профилактика, ранняя диагностика и адекватное лечение туннельных синдромов в зависимости от стадии компрессии нерва. Это основополагающие направления, играющие важную роль в профилактике развития грубых, порой необратимых, двигательных, чувствительных и вегетативных расстройств кисти.

Лечение развившегося КТС должно быть комплексным. Основой его является хирургическое вмешательство. Перспективным является малая инвазивность, безопасность, легкая воспроизводимость в практическом здравоохранении; использование технологий по оптимизации репаративных процессов. Консервативное лечение должно быть направлено на нормализацию обменных процессов и функции срединного нерва.

\section{Литература:}

1. Feng B, Chen K, Zhu X, Ip WY, Andersen LL, Page P, Wang Y. Prevalence and risk factors of self-reported wrist and hand symptoms and clinically confirmed carpal tunnel syndrome among office workers in China: a cross-sectional study. BMC Public Health. 2021 Jan 6. 21(1). 57. doi: 10.1186/s12889-020-10137-1.

2. Белова Н.А. Вегетативные нарушения при идиопатическом карпальном тунельном синдроме . Дис. ...к.м.н. Москва. 2018. 112 с.

3. Юсупова Д.Г., Зимин А.А., Гришина Д.А. Карпальный туннельный синдром: оценка необходимости реабилитационно-восстановительного лечения после эндоскопической декомпрессии срединного нерва в позднем и отдаленном послеоперационном периодах. Нервно-мышечные болезни 2019. 9(4). C.34-43. DOI: 10.17650/22228721-2019-9-4-34-43 
4. Бахтерева Е. В. Компрессионные периферические невропатии верхних конечностей: роль производственных факторов, ранняя диагностика и лечение. Дис. ... к. м.н. 2017. Екатеринбург,. 347 С.

5. Халимова А.А. Тунельный синдром запястья (бзор литературы). Вестник АГИУВ, спецвыпуск. 2013. С.94 - 101.

6. Тондій О.Л., Завальна О.П., Коренєв С.М. Тунельні мононейропатії: етіопатогенез, клініка, діагностика, лікування. Східноєвропейський журнал внутрішньої та сімейної медицини, 2016. № 1. С.68 - 74.

7. Клинические рекомендации по диагностике и хирургическому лечению повреждений и заболеваний перифериской нервной системы. Клинические рекомендации утверждены решением XXXX пленума Правления Ассоциации нейрохирургов России, г. Санкт- Петербург, 16.04.2015 г. Москва. 2015. 42 С.

8. Скоромец А.А. Туннельные компрессионно - ишемические моно-и мультиневропатии. Библиотека врача-специалиста. Неврология. 2019. $32 \mathrm{c}$.

9. Martinoli C., Bianchi S., Nebiolo M. et al. US of nerve entrapments in osteofibrous tunnels of the upper and lower limbs // Radiographics. 2000. V. 20. P. 199-217.

10. Салтыкова В.Г., Шток А.В. Возможности высокоразрешающего ульразвукового сканирования в диагностике состояния структур карпального канала при развитии туннельного синдрома. Ультразвуковая и функциональная диагностика 2009. № 4. С. 47-58

11. Mondelli M., Filippou G., Gallo A., Frediani B. Diagnostic utility of ultrasonography versus nerve conduction studies in mild carpal tunnel syndrome. Arthritis Care and Research. 2008. 59(3). P. 357-66. DOI: 10.1002/art.23317. PMID: 18311762

12. Кириллова Э.Р. Возможности ультразвукового исследования в диагностике синдрома карпального канала. Практическая медицина 2017. 8(109). P.76-79.

13. Fowler J. R., Gaughan J. P., Ilyas A. M. The sensitivity and specificity of ultrasound for the diagnosis of carpal tunnel syndrome: a meta-analysis. Clinical Orthopaedics and Related Research. 2011. 469(4). P.1089-94. DOI: 10.1007/s11999-010-1637-5. PMID 20963527

14. Larsen M.B., Sørensen A.I., Crone K.L. et al. Carpal tunnel release: a randomized comparison of three surgical methods. J Hand Surg Eur. 2013;(38):646-650.

15. Гильвег А. С., Парфенов В. А. Синдром запястного канала в пожилом возрасте // Доктор.Ру. 2017. № 1 (130). с. 30-34.

16. Calotta N.A., Lopez J., Deune E.G. Improved surgical outcomes with endoscopic carpal tunnel release in patients with severe median neuropathy. Hand (N Y). 2017. (12). P. 252-257. 
17. Gumustas S.A., Ekmekci B., Tosun H.B. et al. Similar effectiveness of the open versus endoscopic technique for carpal tunnel syndrome: a prospective randomized trial. Eur J Orthop Surg Traumatol. 2015. (25). P. 1253-1260.

18. Vasiliadis H.S., Georgoulas P., Shrier I. et al. Endoscopic release for carpal tunnel syndrome. Cochrane Database Syst Rev. 2014. (1). CD008265

19. Sayegh E.T., Strauch R.J. Open versus endoscopic carpal tunnel release: a meta-analysis of randomized controlled trials. Clin Orthop Relat Res. 2015. 473(3). P. 1120-1132

DOI https://doi.org/10.30525/978-9934-26-113-8-5

\title{
ЕФЕКТИВНІСТЬ ЗАСТОСУВАННЯ ФІЗИЧНОЇ ТЕРАПІЇ ДЛЯ ВІДНОВЛЕННЯ ФУНКЦІОНАЛЬНОГО РУХУ У ПАЦІЕНТІВ ПІСЛЯ ІНСУЛЬТУ ЗІ СПАСТИЧНІСТЮ ВЕРХНЬОЇ КІНЦІВКИ
}

\author{
Гомола А. В. \\ асистент кафедри біобезпеки $і$ здоров'я людини, аспірант \\ Національний технічний університет Украӥни «Київський \\ політехнічний інститут імені Ігоря Сікорського» \\ Антонова-Рафі Ю. В. \\ кандидат технічних наук, доцент, \\ доиент кафедри біобезпеки $і$ здоров'я людини \\ Національний технічний університет Украӥни «Київський \\ політехнічний інститут імені Ігоря Сікорського» \\ Худецький I. Ю. \\ доктор медичних наук, професор, \\ завідувач кафедри біобезпеки і здоров'я людини \\ Національний технічний університет Украӥни «Київський \\ політехнічний інститут імені Ігоря Сікорського» \\ м. Київ, Украӥна
}

Вступ. Найбільш частою причиною, обмеження повсякденної діяльності особи з наслідками гострого порушення мозкового кровообігу $\epsilon$ когнітивні та рухові порушення. Третина пацієнтів зіткнулись 3 проблемою спастичності м'язів, яка у ранньому періоді потребує уваги, а 24 